\title{
Significance of Primary Malignant Tumors on the Outcome of Patients With Resected Gastrointestinal Stromal Tumors
}

\author{
SHUZO KOHNO $^{1}$, HIROAKI AOKI $^{1}$, MASAICHI OGAWA ${ }^{1}$, \\ KAZUHIKO YOSHIDA ${ }^{1}$ and KATSUHIKO YANAGA ${ }^{2}$ \\ ${ }^{1}$ Department of Surgery, The Jikei University Katsushika Medical Center, Tokyo, Japan; \\ ${ }^{2}$ Department of Surgery, The Jikei University School of Medicine, Tokyo, Japan
}

\begin{abstract}
Aim: This study aimed to clarify the significance of primary malignant tumors for the outcome of resected gastrointestinal stromal tumors (GISTS). Patients and Methods: The medical history, pathological findings and prognosis of 66 patients with GISTs resected at our institute between January 2003 and December 2018 were investigated retrospectively and compared statistically. Results: Among 66 patients with GISTs, 24 (36\%) had concomitant malignant tumors. In an average study period of 57 months, one patient died from GIST, seven from other malignant tumors, and one from another disease. Only coexistence of GIST and other malignant tumors was recognized as a prognostic factor. Increasing age was significantly correlated with other malignant tumor in combination with GIST. When comparing patients with GIST alone and GIST with other malignant tumors, the latter showed significantly poorer prognosis. Conclusion: Coexistence of other malignant tumors was commonly observed in patients with GIST, and was associated with poorer prognosis. This association should be carefully considered and monitored in patients with GISTs.
\end{abstract}

Gastrointestinal stromal tumors (GISTs) are the most common mesenchymal tumors of the digestive tract $(1,2)$. The prognosis of GISTs has improved due to the clarification of etiology and progress with specific treatments. A good prognosis has been observed for patients with low-risk GISTs $(3,4)$. Establishment of treatment has increased the rate of

This article is freely accessible online.

Correspondence to: Shuzo Kohno, MD, Ph.D., Associate Professor of Surgery of Department of Surgery, The Jikei University Katsushika Medical Center, 6-41-2 Aoto, Katsushika-ku, Tokyo 125-8061, Japan. Tel: +81 336032111, Fax: +81 0338389945, e-mail: s-kohno@jikei.ac.jp

Key Words: Gastrointestinal stromal tumor, second malignancy, prognostic factor, second cancer. resection of small-size GIST, and the number of operations for early GISTs has increased. The incidence of GISTs and other malignant tumors is considered high (5-10). The pathogenic relationship between GIST and other malignant tumors has been investigated, but is incompletely understood. The purpose of this study was to clarify the significance of primary malignant tumors for the outcome of resected GISTs

\section{Patients and Methods}

Retrospective analysis was performed on all 66 patients with GIST surgically treated at our hospital between January 2003 and December 2018. The diagnosis, treatment, and follow-up were evaluated based on contemporary standards and more, recently based on the latest guideline (11). The histological diagnosis of all GISTs had been confirmed by the Pathology Department of our hospital. All stromal tumors were diagnosed using immunohistochemistry. The tumors were classified according to the risk categories proposed by Miettinen et al. (12) and the TNM classification (13). All clinical records and pathological reports for each case were reviewed.

Statistical analysis was performed using SPSS statistics ver. 22.0 (IBM Japan, Ltd., Tokyo, Japan). Cox proportional hazards model was used for factor analysis for survival of patients with GIST. Comparisons between patients with GIST alone and GIST with other malignant tumor were performed using Fisher's exact test, unpaired $t$-tests, Mann-Whitney $U$-test and the chi-square test. In the survival analyses, the end-points were evaluated according to survival from first GIST resection. Survival curves were calculated using the Kaplan-Meier method (14). Between-group comparisons were performed using the log-rank test.

\section{Results}

The background data of all stud patients with resected GIST are shown Table I. The patients consisted of 35 men and 31 women, aged 33-87 (average $=65.8$ ) years. In the TNM risk classification, the majority of patients (40/66) were classified at risk level I, and only three at level IV. After a median followup of 57 months, 57 patients had survived without any recurrence, one died of recurrent GIST, seven died of other malignant diseases, and one died without GIST recurrence. Two patients underwent surgery several times for GIST 
Table I. Background characteristics of the study patients ( $n=66)$.

\begin{tabular}{lcc}
\hline Characteristic & & Value \\
\hline Age, years & Mean (range) & $66(33-87)$ \\
Gender, n (\%) & Male & $31(47 \%)$ \\
& Female & $35(53 \%)$ \\
Size, mm & Mean \pm SD & $51.4 \pm 37.6$ \\
Mitotic count, n/HPF & Mean \pm SD & $4.4 \pm 8.7$ \\
WHO (UICC) classification, n (\%) & IA, IB & $40(61 \%)$ \\
& II & $11(17 \%)$ \\
& IIIA, IIIB & $12(18 \%)$ \\
& IV & $3(5 \%)$ \\
Miettinen GIST classification & None & 9 \\
& Very low & 22 \\
& Low & 13 \\
& Moderate & 8 \\
Imatinib administration & High & 14 \\
& Yes & 14 \\
Other cancer type & No & 52 \\
& Yes & 24 \\
& No & 42 \\
\hline
\end{tabular}

WHO (UICC): World Health Organization (Union for International Cancer Control).

Table II. Cox proportional hazards model for death.

\begin{tabular}{lcccc}
\hline Characteristic & & HR & $95 \%$ CI & $p$-Value \\
\hline Age & Per 1-year increase & 1.025 & $0.964-1.090$ & 0.432 \\
Gender & Male & 0.944 & $0.253-3.527$ & 0.932 \\
& Female & 1.000 & Ref & \\
Size & Per 1 mm increase & 0.992 & $0.971-1.014$ & 0.486 \\
Mitotic count & </HPF & 1.000 & Ref & \\
& $\geq 5 / \mathrm{HPF}$ & 1.530 & $0.410-5.718$ & 0.527 \\
WHO (UICC) & IA, IB & 1.000 & Ref \\
classification & II & 0.642 & $0.075-5.518$ & 0.686 \\
& IIIA, IIIB & 1.248 & $0.242-6.441$ & 0.792 \\
& IV & 2.684 & $0.311-23.168$ & 0.369 \\
& Per increase & 1.240 & $0.646-2.381$ & 0.519 \\
Miettinen GIST & None, very & 1.000 & Ref & \\
risk classification & low, low & & & \\
& Moderate & n.c. & - & \\
& High & 1.590 & $0.397-6.370$ & 0.513 \\
Imatinib & Moderate/high & 1.036 & $0.258-4.162$ & 0.960 \\
administration & Yes & 1.000 & Ref & \\
Other cancer & No & 1.693 & $0.450-6.373$ & 0.436 \\
& No & 1.000 & Ref & \\
& Yes & 4.880 & $1.008-23.626$ & 0.049 \\
\hline
\end{tabular}

GIST: Gastrointestinal stromal tumor; WHO (UICC): World Health Organization (Union for International Cancer Control).

recurrence, one of whom underwent resection of recurrent intra-abdominal tumors twice, administered imatinib mesylate, and survived for 13 years without GIST recurrence. Another patient underwent a hepatectomy for liver metastases at 3 years and 6 months after gastrectomy and died of GIST 3 months
Table III. Characteristics of patients with only gastrointestinal stromal tumor (GIST) and those with other coexisting malignant tumor types.

\begin{tabular}{lcccc}
\hline & & \multicolumn{3}{c}{ Other malignant tumor } \\
\cline { 3 - 5 } Characteristic & & Yes (n=24) & No (n=42) & $p$-Value \\
\hline Age, years & Mean \pm SD & $70.88 \pm 9.52$ & $62.90 \pm 12.09$ & $0.007^{\mathrm{a}}$ \\
Gender, n & Male & 13 & 22 & $>0.999^{\mathrm{b}}$ \\
& Female & 11 & 20 & \\
Diameter (mm) & Mean \pm SD & $40.50 \pm 32.35$ & $57.60 \pm 39.72$ & $0.078^{\mathrm{a}}$ \\
WHO (UICC) & IA, IB & $14(21 \%)$ & $26(39 \%)$ & $0.765^{\mathrm{b}}$ \\
classification & II & $3(5 \%)$ & $8(12 \%)$ & \\
& IIIA, IIIB & $6(9 \%)$ & $6(9 \%)$ & \\
Mitotic count, & IV & $1(2 \%)$ & $2(3 \%)$ & \\
n (\%) & $<5 / \mathrm{HPF}$ & $9(14 \%)$ & $12(18 \%)$ & $0.584^{\mathrm{b}}$ \\
Miettinen GIST & $\geq 5 / \mathrm{HPF}$ & $15(23 \%)$ & $30(45 \%)$ & \\
classification, & None & $7(11 \%)$ & $2(3 \%)$ & $0.329^{\mathrm{c}}$ \\
n $(\%)$ & Very low & $5(8 \%)$ & $17(26 \%)$ & \\
& Low & $5(8 \%$ & $8(12 \%)$ & \\
& Moderate & $1(2 \%)$ & $7(11 \%)$ & \\
& High & $6(9 \%)$ & $8(12 \%)$ & \\
& None/low & $17(26 \%)$ & $27(41 \%)$ & $0.787^{\mathrm{b}}$ \\
& Moderate/high & $7(11 \%)$ & $15(23 \%)$ & \\
\hline
\end{tabular}

WHO (UICC): World Health Organization (Union for International Cancer Control); SD: standard deviation. aUnpaired $t$-test; 'bFisher's exact test; 'Mann-Whitney $U$-test.

after the hepatectomy. The GISTs were located in the stomach in $88 \%$, intestine in $8 \%$, peritoneum in $2 \%$, rectum in $2 \%$ and duodenum in $2 \%$. The tumor sizes ranged from 5 to 165 (average $=51.4) \mathrm{mm}$. Among the 66 patients, $24(36 \%)$ were diagnosed as having 29 other malignant tumors, including three patients with two other malignant tumors and one patient with three other malignant tumors. The incidence rates of other malignant tumors were $17 \%$ for those located in the stomach, $11 \%$ for the colorectum and anus, 5\% for the liver (cholangiocellular carcinoma, 3\%; hepatocellular carcinoma, $2 \%$ ), $3 \%$ for the bladder, and $2 \%$ each for the esophagus, larynx, breast, prostate, ureter, ovary, and lung. Among the patients with both GISTs and other malignant tumor, eight cases had already been detected before the GIST treatment, 11 had been detected simultaneously, and nine had been detected after the GIST treatment. Among the 11 patients with simultaneous detection of GISTs and other malignant tumors, six had gastric cancer and one had esophageal cancer. Among the seven resected GISTs with gastric or esophageal cancer at the same time, three were not diagnosed preoperatively, and the average tumor diameter was small $(16 \mathrm{~mm})$. For the seven patients who died of malignant tumor other than GISTs, four died of stomach cancer and three of liver cancer. For the patients with GIST without other malignancies, one died of their disease at 3 years and 9 months postoperatively.

To investigate the prognoses of patients with GIST, patient age, gender, tumor diameter, mitotic rate, Miettinen risk 


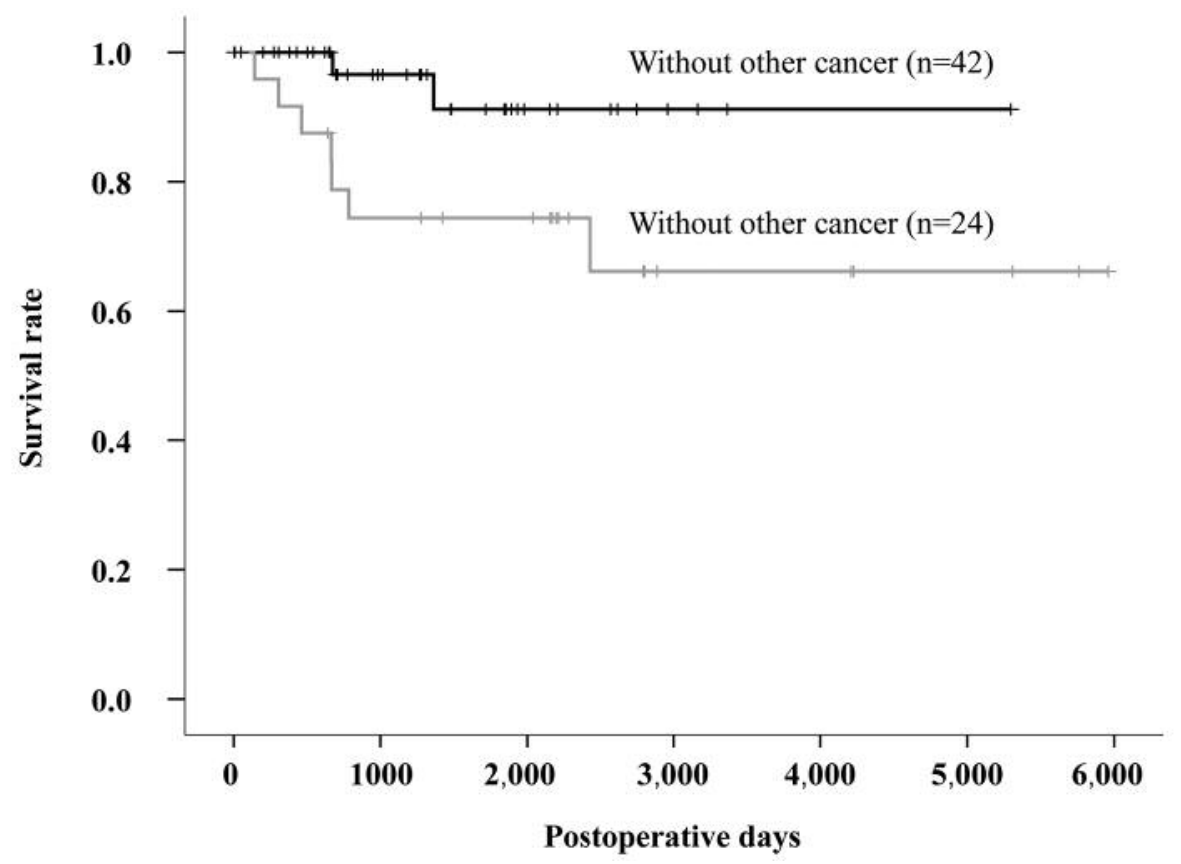

Figure 1. Kaplan-Meier analysis of disease-specific survival for patients with gastrointestinal stromal tumor (GIST) alone and those with other coexisting malignant tumors $(p=0.029)$. The average disease-specific survival observation period for those with GIST was 4,926.6 days $(95 \%$ confidence intervaI=4,429.5-5,423.7) for patients with GIST alone and 4,270.6 days for patients with additional malignancies.

classification, TNM classification, and coexistence of other malignant tumors were investigated (Table II). In the prognostic evaluation based on survival analysis using prognostic factors for GIST, no significant difference was observed in age, gender, tumor diameter, mitotic rate, and risk classification; only the coexistence of other malignant tumor showed a statistically significant association with poorer survival.

Differences between patients with GISTs with and without other malignant tumors are shown in Table III. The average age was significantly higher for the patients with other malignant tumors than those without. The tumor diameter, gender ratio and Miettinen GIST classification did not differ between the groups.

Twenty patients treated with imatinib mesylate after GIST resection had been followed up for an average of 1,425 days, and 46 patients not treated with imatinib mesylate had been followed up for an average of 1,855 days. The average age, gender, and GIST classification stages of both groups did not significantly differ (data not shown). The incidence of other malignant tumors after GIST resection also did not significantly differ between those receiving imatinib mesylate $(2 / 20)$ and those not $(7 / 46)(p=0.576)$.

A comparison between survival curves of patients with GIST alone and those with other malignant tumors is shown in Figure 1. Patients with GIST alone appeared to have a significantly superior disease-free survival.

\section{Discussion}

This study enrolled 66 patients with GIST who were treated surgically. A high incidence (36\%) of coexistence of GISTs with other malignant tumors was observed. On comparing patients with GISTs with and without other malignant tumors, the former were found to be older and have significantly worse prognoses but no differences in GIST staging were observed between the groups.

Many cases of GIST with other malignant tumors have been reported. The incidence rate of additional malignancies ranges from 4.5 to $43 \%(5-10,15-17)$. In a recent large-scale study, the occurrence of secondary tumors was reported to be increasing because older patients were expected to develop malignancies; indeed, $25.2 \%$ of older adults (aged $\geq 65$ years) newly diagnosed with cancer had a history of prior cancer (18). In the current study, the mean age at the time of GIST surgery was 65.8 years. The frequency of GIST with other malignant tumors $(36 \%)$ was considered high, although the frequency was different from the evaluation method in the previous study. Moreover, the number of GIST cases coexisting with other malignant tumors was considered to be increased due to the extended follow-up period.

Others have investigated the type and chronology of other malignant tumors in relation to $\operatorname{GIST}(6,7,9)$. No clear trends have been established but many GIST cases coexisted with gastric cancer. A report demonstrated that GISTs were 
present with high frequency $(35 \%)$ in the resected stomach of patients with gastric cancer (19). The size of GIST malignancies simultaneously resected with other malignancies tended to be small and the grade low (20). Therefore, pathological examination of surgical specimens from gastric cancer surgery may find GIST and increase the number of patients with GIST. Reports on GISTs simultaneous with other gastrointestinal cancer types have revealed worse prognosis than that of $\operatorname{GIST}$ alone $(21,22)$.

GISTs commonly activate the mutations of the gene encoding KIT proto-oncogene, receptor tyrosine kinase (KIT). Although hereditary GIST syndrome has been reported (23, $24)$, the frequency of occurrence is low. Some reports also revealed that specific genetic abnormalities occurred when neurofibromatosis type 1 or neuroendocrine tumor merged with GIST $(25,26)$. No mutational correlation was reported between GISTs and the coexistence of tumors of different histogenesis regarding KIT and platelet-derived growth factor receptor alpha genes (27). Thus, further genetic research is expected.

In the current study, the mortality rate of patients with GIST was very low. GIST prognosis is determined by metastasis, tumor size, number of mitoses, and degree of risk (12). According to the therapeutic guidelines, the ratio of low-risk patients increases with the increasing resection of smaller and less malignant GISTs. A good prognosis is observed after surgery for those with low-risk GISTs (28). In the current study, three patients were classified as risk class IV according to the TNM classification, of whom only one died. The other two patients survived for a long period due to multidisciplinary treatment. The proportion of patients in the high-risk group was extremely low; therefore, we consider that the prognostic outcome of GIST itself was not reflected in the prognostic determination and instead was influenced by other factors. In the current study, the prognosis of GIST tended to be determined by the other malignant tumors that coexisted with GIST.

The prognosis of GIST is improved by tumor resection and adjuvant drug therapy (imatinib mesylate administration) (29, 30). Improvement of the prognosis in the high-risk patients is likely to have been due to treatment with imatinib mesylate. Guiliani et al. showed an increase in secondary malignancies after treatment of GISTs with imatinib mesylate, which suggested that the prognosis was extended because of imatinib mesylate administration (31). The low occurrence of secondary malignancies after imatinib mesylate administration in the current study may be due to the short follow-up period.

Based on the above considerations, we believe that the coexistence of other malignant tumors negatively influences the prognosis of patients with GIST. Therefore, a stricter follow-up for other malignancies should be conducted in patients with GIST because of their long-term survival and the fact that prognosis seems to be adversely affected by the coexistence of other malignant tumors.

\section{Conclusion}

Co-existence of GIST and other malignant tumors is often observed and seems to adversely affect the outcome of GIST.

\section{Conflicts of Interest}

The Authors have no conflicts of interest to declare regarding this study.

\section{Authors' Contributions}

Shuzo Kohno designed the study and wrote the article. Shuzo Kohno and Hiroaki Aoki evaluated clinical data. Shuzo Kohno, Hiroaki Aoki, Masaichi Ogawa, Kazuhiko Yoshida and Katsuhiko Yanaga interpreted the results.

\section{References}

1 Miettinen $\mathrm{M}$ and Lasota $\mathrm{J}$ : Gastrointestinal stromal tumorsdefinition, clinical, histological immunohistochemical and molecular genetic feature and differential diagnosis. Virchows Arch 438: 1-12, 2001. PMID: 11213830.

2 Miettinen $\mathrm{M}$ and Lasota J: Gastrointestinal stromal tumors: Review on morphology, molecular pathology, prognosis, and differential diagnosis. Arch Pathol Lab Med 130: 1466-1478, 2006. PMID: 17090188. DOI: 10.1043/1543-2165(2006)130 [1466:GSTROM]2.0.CO;2

3 Schmieder M, Henne-Bruns D, Mayer B, Knippschild U, Rolke C, Schwab $M$ and Kramer K: Comparison of different risk classification systems in 558 patients with gastrointestinal stromal tumors after R0-resection. Front Pharmacol 7: 504, 2016. DOI: $10.3389 /$ fphar.2016.00504

4 Bischof DA, Kim Y, Behman R, Karanicolas PJ, Quereshy FA, Blazer DG $3^{\text {rd }}$, Maithel SK, Gamblin TC, Bauer TW and Pawlik TM: A nomogram to predict disease-free survival after surgical resection of GIST. J Gastrointest Surg 18: 2123-2129, 2014. PMID: 25245766. DOI: 10.1007/s11605-014-2658-2

5 Murphy JD, Ma GL, Baumgartner JM, Madlensky L, Burgoyne AM, Tang C-M, Martinez ME and Sicklick JK: Increased risk of additional cancers among patients with gastrointestinal stromal tumors. A population-based study. Cancer 121: 29602967, 2015. PMID: 25930983. DOI: 10.1002/cncr.29434

6 Vassos N, Agaimy A, Hauenberger W and Croner RS: Coexistance of gastrointestinal stromal tumor (GIST) and malignant neoplasms of different origin: Prognostic implications. Int J Surg 12: 371-377, 2014. PMID: 24632413. DOI: 10.1016/j.ijsu.2014.03.004

7 Agaimy A, Wunsch PH, Sobin LH, Lasota J and Miettinen M: Occurrence of malignancies in patients with gastrointestinal stromal tumor. Semin Diagn Pathol 23: 120-129, 2014. PMID: 17193825. DOI: org/10.1053/j.semdp.2006.09.004

8 Liszka L, Pajak EZ, Pajak J, Golka D and Huszuno J: Coexistence of gastrointestinal stromal tumors with other neoplasms. J Gastroenterol 42: 641-649, 2007. PMID: 17701127. DOI: 10.1007/s00535-007-2082-4

9 Ferreira SS, Werutsky G, Toneto MG, Alves JM, Pianta CD, Breunig RC, Rocha AB, Grivicich I and Garicochea B: Synchronous gastrointestinal stromal tumors (GIST) and other primary cancers: Case series of a single institution experience. 
Int J Surg 8: 314-317, 2010. PMID: 20380900. DOI: 10.1016/ j.ijsu.2010.03.008

10 Hechtman JF, DeMattero R, Nafa K, Chi P, Arcila ME, Dogan S, Oultache A, Chen W and Hameed M: Additional primary malignancies in patients with gastrointestinal stromal tumor (GIST): A clinicopathologic study of 260 patients with molecular analysis and review of the literature. Ann Surg Oncol 22: 26332639, 2015. PMID: 25564173. DOI: 10.1245/s10434-014-4332-Z

11 Nishida T, Blay JY, Hirota S, Kitagawa Y and Kang YK: The standard diagnosis, treatment, and follow-up of gastrointestinal stromal tumors based on guidelines. Gastric Cancer 19: 3-14, 2016. PMID: 26276366. DOI: 10.1007/s10120-015-0526-8

12 Miettinen M, Sobin LH and Lasota J: Gastrointestinal stromal tumors of the stomach: A clinicopathologic, immunohistochemical, and molecular genetic study of 1765 cases with long-term follow-up. Am J Surg Pathol 29: 52-68, 2005. PMID: 15613856.

13 Sobin LH, Gospodarowicz $M$ and Wittekind Ch. (eds.): Gastrointestinal Stromal Tumor (GIST). International Union Against Cancer TNM Classification of Malignant Tumors Seventh Edition. New York: Wiley, 2010.

14 Kaplan EL and Meier K: Nonparametric estimation from incomplete observations. J Am Stat Assoc 53: 457-481, 1958. DOI: $10.2307 / 2281868$

15 Smith MJ, Smith HG, Mahar AL, Law C and Ko YJ: The impact of additional malignancies in the patients diagnosed with gastrointestinal stromal tumors. Int J Cancer 139: 1744-1751, 2016. PMID: 27299364. DOI: 10.1002/ijc.30231

16 Pandurengan RK, Dumont AG, Araujo DM, Ludwig JA, Ravi V, Patel S, Gaber J, Benjamin RS, Strom SS and Trent JC: Survival of patients with multiple primary malignancies: A study of 783 patients with gastrointestinal stromal tumor. Ann Oncol 21: 2107 2111, 2010. PMID: 20348145. DOI: 10.1093/annonc/mdq078

17 Kramer K, Wolf S, Mayer, B,Schmidt SA, Agamy A, HanneBruns D, Knippschild U, Schawb $M$ and Schmieder $M$ : Frequency, spectrum and prognostic impact of additional malignancies in patients with gastrointestinal stromal tumor. Neoplasia 17: 134-140, 2015. PMID: 25622906. DOI: 10.1016/ j.neo.2014.12.001

18 Murphy CC, Gerber DE and Pruitt SL: Prevalence of prior cancer among persons newly diagnosed with cancer. An initial report from the Surveillance, Epidemiology, and End Results program. JAMA Oncol 4(6): 832-836, 2018. PMID: 29167866. DOI: $10.1001 /$ jamaoncol.2017.3605

19 Kawanowa K, Sakuma Y, Sakurai S, Hishima T, Iawsaki Y, Saito K, Hosoya $Y$, Nakajima $T$ and Funeta: High incidence of microscopic gastrointestinal stromal tumors in the stomach. Hum Pathol 37: 1527-1535, 2006. PMID: 16996566. DOI: 10.1016/ j.humpath.2006.07.002

20 Liu Z, Liu S, Zheng G, Yang J, Hong L, Sun L, Fan D, Zhang $\mathrm{H}$ and Feng F: Clinicopathological features and prognosis of coexistence of gastric gastrointestinal stromal tumor and gastric cancer. Medicine 95(45): e5373, 2016. PMID:27828865. DOI: 10.1097/MD .0000000000005373

$21 \mathrm{Du}$ J, Shen N, He HS, Fu XL, Wang JZ and Mao CZ: Synchronous gastrointestinal cancer and gastrointestinal stromal tumors: A single-institution experience. World J Surg Oncol 14: 130, 2016. PMID: 27129592. DOI: 10.1186/s12957-016-0882-9

22 Chan CH, Cools-Lartigue J, Marcus VA, Feldman LS and Ferri LE: The impact of incidental gastrointestinal stromal tumors on patients undergoing resection of upper gastrointestinal neoplasms. Can J Surg 55: 366-370, 2012. PMID: 22992402. DOI: $10.1503 /$ cjs.009111

23 Veiga I, Silva M, Vieira J, Pinto C, Pinheriro M, Torres L, Soares M, Santos L,Duarte H, Bastos AL, Coutinho C, Dinis J, Lopes $\mathrm{C}$ and Teixeira MR: Hereditary gastrointestinal stromal tumors sharing the KIT exon 17 germline mutation p.Asp820Tyr develop through different cytogenic progression pathway. Genes Chromosomes Cancer 49: 91-98, 2010. PMID: 19847891. DOI: $10.1002 /$ gcc 20720

24 Ricci R: Syndromic gastrointestinal stromal tumors. Hered Cancer Clin Pract 14: 15, 2016. PMID: 27437068. DOI: 10.1186/s13053-016-0055-4

25 Pasini B, Matyakhina L, Bei T, Muchow M, Boikos S, Ferrand B, Carney JA and Stratakis CA: Multiple gastrointestinal stromal and other tumors caused by platelet-derived growth factor receptor alpha gene mutations: A case associated with a germline V561D defect. J Clin Endocrinol Metab 92: 3728-3732, 2007. PMID: 17566086. DOI: 10.1210/jc.2007-0894

26 Mussi C, Schildhaus H-U, Gronchi A, Wardelmann E and Hohenberger P: Therapeutic consequences from molecular biology for gastrointestinal stromal tumor patients affected by neurofibromatosis type 1. Clin Cancer Res 14: 4550-4555, 2008. PMID: 18628470. DOI: 10.1158/1078-0432.CCR-08-0086

27 Arnogiannaki N, Martzoukou I, Kountourakis P, Dimitridis E, Papathanasaki A, Nastoulis E, Gazalidou M, Fida A, Apostolikas $\mathrm{N}$ and Agnantis NJ: Synchronous presentation of GISTs and other primary neoplasms: A single-center experience. In Vivo 24: 109-116, 2010. PMID: 20133985

28 Bucher P, Egger JF, Gervaz P, Ris F, Weintraub D, Villiger $\mathrm{P}, \mathrm{Buhler} \mathrm{LH}$ and Morel $\mathrm{Ph}$ : An audit of surgical management of gastrointestinal stromal tumors (GIST). Eur J Surg Oncol 32: 310314, 2006. PMID: 16414236. DOI: 10.1016/j.ejso.2005.11.021

29 DeMatteoRP, Ballman KV, Antonescu CR, Corless C, Kolesnikov V, Mehren M McCarter MD, Norton J, Maki RG, Pisters PWT, Demetri GD, Brennan MF and Owazar K: Longterm results of adjuvant imatinib mesylate in localized, high-risk, primary gastrointestinal stromal tumor (GIST): ACOSOG Z9000 (Alliance) intergroup phase 2 trial. Ann Surg 258: 422-429, 2013. PMID: 23860199. DOI: 10.1097/SLA.0b013e3182a15eb7

30 Casali PG, Le Cesne A, Poveda Valasco A, Rutkowski P, Hohenberger P, Fumagalli E, Judson IR, Italiano A, Gelderblom H, Adenis A, Hartmann JT, Duffaund F, Goldstein D, Bronto JM, Gronchi A, Tos APD, Marreaud S, vander Graaf WTA, Zalcberg JR, Litiere $S$ and Blay JY: Time to definitive failure to the first tyrosine kinase inhibitor in localized GI stromal tumors treated with imatinib as an adjuvant: A European Organisation for Research and Treatment of Cancer Soft Tissue and Bone Sarcoma Group Intergroup randomized trial in collaboration with the Australasian Gastro-Intestinal Trials Group, UNICANCER, French Sarcoma Group, Italian Sarcoma Group, and Spanish Group for Research on Sarcomas. J Clin Oncol 33: 4276-4283, 2015. PMID: 26573069. DOI: 10.1200/JCO.2015.62.4304

31 Giuliani J and Bonetti A: Gastrointestinal stromal tumors and second primary malignancies before the introduction of imatinib mesylate. Chin J Cancer Res 25: 486-487, 2013. PMID: 24255568. DOI: $10.3978 /$ j.issn.1000-9604.2013.10.13

Received February 13, 2020

Revised February 28, 2020 Accepted March 4, 2020 